\title{
Representações discursivas sobre internaciona- lização por professores de inglês em formação continuada
}

\author{
Lauro Sérgio Machado Pereira \\ Instituto Federal do Norte de Minas Gerais (Brasil) \\ Kléber Aparecido da Silva \\ Universidade de Brasília (Brasil)
}

\section{Resumo}

Neste artigo, analisam-se as representações discursivas sobre a internacionalização da educação por professores de inglês da Rede Federal de Educação Profissional, Científica e Tecnológica (RFEPCT) participantes do Programa SETEC-CAPES/NOVA de formação continuada. Os pressupostos teórico-metodológicos orientam-se pela Análise de Discurso Crítica (FAIRCLOUGH, 2003; $2016)$ e pela Internacionalização Crítica (VAVRUS; PEKOL, 2015; STEIN, 2019), que encontram pontos de intersecção na mudança social por intermédio do discurso como prática social e nos princípios da ética, da equidade e da justiça social. Um questionário estruturado online foi aplicado em um grupo de professores de inglês a fim de possibilitar a geração dos dados. As respostas dos docentes participantes sinalizaram representações de internacionalização pautadas por aspectos benéficos do processo, evidenciando discursos hegemônicos e contra-hegemônicos. $\bigcirc$ estudo possibilitou compreender que delimitar hegemonias e contra-hegemonias nas representações discursivas dos professores participantes acerca da internacionalização é tarefa complexa, pois, nessas representações, coexistem sentidos híbridos e conflitivos.

Palavras-chave: Internacionalização da educação. Formação de professores de inglês. SETEC/ CAPES-NOVA.

\section{The discursive representations about internationalization by teachers of English in continuing education}

\begin{abstract}
In this article, we analyze the discursive representations on the internationalization of education by English teachers from the Federal Network of Vocational, Scientific and Technological Education (RFEPCT) participating in the SETEC-CAPES/NOVA Continuing Education Program. Critical Discourse Analysis (FAIRCLOUGH, 2003; 2016) and Critical Internationalization (VAVRUS; PEKOL, 2015; STEIN, 20191, which find points of intersection in social change through discourse as a social practice and in the principles of ethics, equity, and social justice, guide the theoretical and methodological assumptions of this study. A structured online questionnaire was applied to a group of English teachers to enable data generation. The responses of the participating teachers signaled representations of internationalization based on beneficial aspects of the process,
\end{abstract}


Representações discursivas sobre internacionalização por professores de inglês em formação continuada

showing hegemonic and counter-hegemonic discourses. The study made it possible to understand that delimiting hegemonies and counter-hegemonies in the discursive representations of the participating teachers about internationalization is a complex task because, in these representations, hybrid and conflicting meanings coexist.

Keywords: Internationalization of education. English language teachers' education. SETEC/ CAPES-NOVA.

\section{Las representaciones discursivas sobre la internacionalización por los profesores de inglés en formación continua}

\section{Resumen}

Este artículo analiza las representaciones discursivas sobre la internacionalización de la educación de los profesores de inglés de la Red Federal de Enseñanza Profesional, Científica y Tecnológica (RFEPCT) participantes en el programa de formación continua SETEC-CAPES/ NOVA. Los supuestos teóricos y metodológicos se guían por el Análisis Crítico del Discurso (FAIRCLOUGH, 2003; 2016) y por la Internacionalización Crítica (VAVRUS; PEKOL, 2015; STEIN, 2019), que encuentran puntos de intersección en el cambio social a través del discurso como práctica social y en los principios de ética, equidad y justicia social. Se aplicó un cuestionario estructurado en línea a un grupo de profesores de inglés con el fin de posibilitar la generación de datos. Las respuestas de los profesores participantes señalaron representaciones de internacionalización basadas en aspectos beneficiosos del proceso, evidenciando discursos hegemónicos y contrahegemónicos. El estudio permitió comprender que delimitar las hegemonías y contrahegemonías en las representaciones discursivas de los profesores participantes acerca de la internacionalización es una tarea compleja, ya que, en dichas representaciones, coexisten sentidos híbridos y conflictivos.

Palabras clave: Internacionalización de la educación. Formación de profesores de inglés. SETEC/CAPES-NOVA.

\section{Introdução}

A internacionalização da educação - é um constructo complexo e polissêmico que remete a diferentes processos e aspectos da instituição educacional, quais sejam: a internacionalização do currículo e da pesquisa, a abertura de campi em outros países, a educação a distância, a mobilidade acadêmica, entre outros (PERROTTA, 2016). Esses processos objetivam integrar uma dimensão internacional e intercultural à educação no intuito de responder às demandas voltadas para o desenvolvimento sustentável do planeta (MOROSINI, 2019). 
A entrada da globalização na pauta dos sistemas educacionais (SOUZA, 2018) tem contribuído para que instituições e agências governamentais e privadas adotem a internacionalização como estratégia necessária. Com isso, nos últimos anos, observou-se o fortalecimento dos debates sobre o tema, e o aumento de iniciativas do governo brasileiro na pesquisa mediante ações de mobilidade acadêmica internacional. No bojo dessas iniciativas, os Programas Ciências sem Fronteiras (CsF) e ldiomas sem Fronteiras (IsF) contribuíram para a expansão e a internacionalização da ciência e tecnologia, da inovação e da competitividade brasileira.

Acerca das iniciativas de internacionalização da formação de professores brasileiros de línguas, Dutra (2015) salienta que são poucos os editais para programas direcionados a esse propósito. Entretanto, especificamente no caso da internacionalização da formação de professores de inglês, o governo federal, mediante acordo de cooperação entre Brasil e Estados Unidos em 2010 (BRASIL, Decreto n 7.176 de 12 de maio de 2010), executou o Programa SETEC-CAPES/NOVA (doravante Programa), em 2016, no âmbito da Rede Federal de Educação Profissional Científica e Tecnológica (RFEPCT). Esse Programa, regido pelo texto Chamada Pública SETEC/MEC nº 01/2015, de 22 de setembro de 2015 (doravante texto Chamada Pública), objetivou capacitar professores de inglês na instituição Northern Virginia Community College, nos Estados Unidos.

Apesar de o texto Chamada Pública não apresentar objetivos relacionados a ações de internacionalização, observa-se na descrição do objeto do Programa, bem como na relação de obrigações dos candidatos selecionados, uma explicitação de que os conhecimentos adquiridos pelos professores beneficiados deveriam ser aplicados em suas instituições de origem a fim de contribuir com ações e atividades de ensino, de pesquisa, de extensão, de inovação e de internacionalização.

Diante disso, e considerando o fenômeno da geopolíitica do conhecimento, que contribui para a mercantilização da educação e consequentemente provoca danos em países que se encontram em condições periféricas (LIMA; CONTEL, 2011 1, analisamos as representações discursivas sobre a internacionalização de professores de inglês participantes da $1^{\alpha}$ edição do Programa. O objetivo se justifica, pois, uma vez que na geopolíitica do conhecimento os fluxos legitimados de produção de pesquisa encontram-se polarizados em países ricos (NEZ; FRANCO, 2018), os professores, que fizeram a capacitação nos 
Representaçães discursivas sobre internacionalização por professores de inglês em formação continuada

Estados Unidos, podem naturalizar discursos, conhecimentos, atitudes e valores assimilados nesse país, aplicando-os em suas práticas sem reflexão crítica.

Ademais, partindo da constatação de Vavrus e Pekol (2015) de que as discussões em torno da representação ficaram ausentes da literatura sobre internacionalização, é pertinente evidenciar as representações discursivas dos professores de inglês que passaram por formação internacional. Com isso, propõem-se encaminhamentos para a construção de uma nova racionalidade que concebe uma internacionalização em prol da formação humana e da transformação social.

Este trabalho discute a internacionalização de uma perspectiva crítica (VAVRUS; PEKOL, 2015, STEIN, 2019), pois considera a educação como prática social capaz de transformar grupos marginalizados. Por intermédio de professores "[...] determinados e capazes de trabalhar dentro e fora de suas salas de aula a fim de mudar as desigualdades que existem tanto no ensino quanto na sociedade como um todo" (DINIZ-PEREIRA; ZEICHNER, 2008, p. 17), pode-se promover justiça social. Dessa forma, no contexto brasileiro, bem como no de outros países em desenvolvimento, é fundamental que a internacionalização da formação de professores de línguas possa se dar nessa perspectiva, com o propósito de promover movimentos significativos de mudança social. Além disso, cabe ressaltar que no caso do inglês, língua com alta demanda pela internacionalização, nota-se a necessidade de conceber estratégias de ensino-aprendizagem que promovam uma educação linguística mais colaborativa e menos impositiva. Isso significa que professores e alunos ensinam e aprendem inglês para construírem oportunidades de mudança em suas localidades e não como mecanismo de assujeitamento e de reprodução de discursos e práticas sociais hegemônicas.

Entendemos que os professores de línguas são agentes políticos influenciados pelas ideologias das políticas educacionais llinguísticas e de internacionalização etc.), de modo que, por seu intermédio, essas políticas podem passar de declarações formais (legislações) para práticas ressignificadas localmente. Nesse sentido, compreender as representações discursivas dos professores de inglês relativas aos discursos de poder que envolvem a internacionalização é crucial para se pensar criticamente em estratégias de educação linguística que vão ao encontro das necessidades dos estudantes brasileiros. 
Este trabalho, de caráter qualitativo, segue os pressupostos teórico-metodológicos da Análise de Discurso Crítica (ADC) de Fairclough (2003; $2016)$ em diálogo com as discussões encontradas em Vavrus e Pekol (2015) e em Stein (2019) a respeito da Internacionalização Crítica (IC). A partir disso, consideramos que, valorizando a perspectiva interdisciplinar da ADC, a relação possível entre a ADC e a IC está no fato de que ambas têm interesses que se tangenciam de alguma maneira, no sentido de que ela dialoga com outras teorias e áreas do conhecimento (MAGALHÃES, 2005). A primeira está interessada na promoção de mudança social a partir do discurso como prática social e a segunda se pauta pela equidade, pela ética e pela justiça social. De posse dessas orientações, procuramos responder à seguinte questão de pesquisa: Como as representações discursivas sobre internacionalização da educação são evidenciadas por professores de inglês participantes do Programa SETEC-CAPES/NOVA?

artigo está organizado da seguinte forma: além desta introdução, incluem-se quatro seções e as considerações finais. A primeira seção apresenta alguns apontamentos a respeito da internacionalização de uma perspectiva crítica, no sentido de que contribui para a justiça social, redução de desigualdades e assimetrias. A segunda discute a internacionalização da formação continuada de professores de inglês sinalizada pelo texto Chamada Pública que orienta o Programa de capacitação docente. A terceira aborda os pressupostos teórico-metodológicos da ADC que orientaram o percurso de geração e análise dos dados. A quarta seção analisa as representações discursivas sobre a internacionalização reverberadas pelos professores participantes.

\section{A internacionalização da educação de uma perspectiva crítica}

Segundo Vavrus e Pekol (2015), em decorrência dos acordos econômicos globais, a maioria das atividades de internacionalização se orienta pelos imperativos econômico e social. No primeiro, as instituições de ensino se beneficiam financeiramente da recepção de estudantes estrangeiros e de acordos internacionais. No segundo, essas instituições promovem uma maior consciência internacional e intercultural entre seus estudantes a fim de que eles possam competir na economia global mediante orientações de sua missão social. 
Representações discursivas sobre internacionalização por professores de inglês em formação continuada

Embora a internacionalização tenha conquistado importância em diversas partes do mundo, as instituições de ensino precisam lidar com governos neoliberais que reduzem o investimento público em suas atividades, forçando-as a se adequar a um reduzido financiamento. Dessa forma, no contexto de países ricos, as instituições se veem obrigadas a adotar estratégias baseadas no mercado, estabelecendo parcerias com indústrias, aumentando as taxas cobradas e comercializando programas e serviços, o que tem contribuído para se manter na liderança. Já no caso das instituições de ensino localizadas em países economicamente frágeis, com escassez de financiamento público, a situação é bastante diferente, pois majoritariamente não dispõem de reputação globalmente reconhecida ou têm dificuldades de acessar recursos financeiros privados para realizar as atividades mais básicas de ensino e pesquisa (VAVRUS; PEKOL, 2015).

Ancorados nos postulados de Vavrus e Pekol (2015) e de Stein (2019), nosso objetivo nesta seção é questionar as abordagens esmagadoramente positivas e despolitizadas de internacionalização, que valorizam a comercialização, a competição, os resultados e a instrumentalização das atividades educacionais e acadêmicas. Diferentemente, propõe-se pensar a internaciona6 lização por uma perspectiva mais ampla e crítica, considerando questões de equidade, de ética e de justiça social, de modo a iluminar as desigualdades entranhadas na internacionalização.

Vista pela ótica crítica, a internacionalização parte das teorias sociais críticas aplicadas à educação e explica como as desigualdades são estruturadas e reproduzidas. Para tanto, o foco está na ideologia, pois nos "[...] ajuda a explicar as dimensões simbólicas e representacionais da internacionalização" (VAVRUS; PEKOL, 2015, p. 7). Para essas estudiosas, o conceito de hegemonia cultural possibilita compreender como as visões de mundo das classes sociais dominantes são naturalizadas pela sociedade, ainda que contribuam para a marginalização da classe trabalhadora.

Neste artigo tomamos o discurso como prática social constituída pela potencialidade de provocar consequências econômicas e políticas por meio das relações de poder. Logo, enquanto prática, a internacionalização não deve ser naturalizada como positiva e politicamente propícia, mas, sim, analisada criticamente a fim de se observar se fomenta assimetrias ou promove relações globais mais justas. Dessa maneira, torna-se possível "[...] identificar a continuação de padrões duradouros de produção eurocêntrica do conhecimento, das 
relações de exploração e do acesso desigual aos recursos" (STEIN, 2019, p. 3). Nessa perspectiva, faz-se necessário orientar decisões públicas e estudos com vistas à internacionalização para o bem público, em uma perspectiva liberal de formação humana; à internacionalização para a solidariedade global, voltada para ações contra a opressão e a marginalização das culturas e dos indivíduos (STEIN, 2019).

Complementando esses apontamentos, Lima e Maranhão (2009) definem a internacionalização como ativa e passiva. A primeira é realizada por países ricos, influencia o sistema mundial de educação e favorece uma internacionalização hegemônica que contribui para que haja desequilíbrios e descompassos entre os ganhos que países centrais e periféricos obtém. Por outro lado, a internacionalização passiva está presente em países semiperiféricos e periféricos da economia mundial e é empreendida com o propósito de possibilitar uma experiência acadêmica e/ou profissional internacional a estudantes, professores e técnicos-administrativos, no sentido de acessarem uma formação em grandes centros acadêmicos, contribuindo com a modernização de alguns setores da instituição educacional. Enquanto na internacionalização ativa temos a implantação de políticas de Estado e a exportação de programas educacionais, na internacionalização passiva os recursos provenientes de países periféricos ajudam a financiar a educação de países centrais. Desse modo, é importante resistir à ideia de que a internacionalização é um efeito naturalizado e justificável pela globalização da economia-mundo, pois nem sempre ela se pauta por processos de integração, solidariedade e sustentabilidade.

Em diversas instituições de ensino, a internacionalização tem sido vista como uma estratégia que produz resultados positivos, o que naturaliza sentidos e práticas destituídas de criticidade por parte de alguns agentes da internacionalização (docentes, pesquisadores, gestores, técnicos administrativos, entre outros). Nesse caso, se instaura o sentido de serviço na internacionalização que pode ser comercializado a fim de elevar a posição da instituição nos rankings internacionais de qualidade acadêmica, o que ocorre mediante ações de mobilidade discente e docente, de parcerias entre pesquisadores nacionais e estrangeiros, de publicações, principalmente em inglês, em periódicos internacionais etc. Essa perspectiva de internacionalização é validada por organismos multilaterais, tais como a Organização para a Cooperação e Desenvolvimento Econômico (OCDE) e o Banco Mundial, desconsiderando reflexões sobre os 
benefícios para uma democratização educacional (BRANDENBURG; DE WIT, 20111 .

A naturalização dos aspectos positivos da internacionalização tem sido questionada, com a proposta de um olhar para o fenômeno a partir de lentes críticas. Nessa direção, Leal, Moraes e Oregioni (2018) propõem dezessete categorias para a análise crítico-reflexiva da hegemonia e da contra-hegemonia nesse cenário, partindo do pressuposto de que a internacionalização está alicerçada na matriz dominante de poder, e de que a educação é um campo influenciado por princípios econômicos. Dentre essas categorias, duas merecem destaque para o propósito deste trabalho, conforme apresentamos no quadro 1 :

\section{Quadro 1}

\section{As dimensões da internacionalização}

\begin{tabular}{|c|c|c|}
\hline Categoria & Hegemônica & Contra-hegemônica \\
\hline $\begin{array}{l}R a t i o n a l \text { e } \\
\text { (Motivações } \\
\text { Interesses) pre- } \\
\text { dominantes na } \\
\text { internacionalização }\end{array}$ & $\begin{array}{l}\text { Segue os preceitos da go- } \\
\text { vernança internacional } \\
\text { neoliberal. } \\
\text { - Rationales econômicas e } \\
\text { instrumentais para atender } \\
\text { aos interesses do mercado } \\
\text { capitalista mundial. }\end{array}$ & $\begin{array}{l}\text { Contrária à mercantiliza- } \\
\text { ção da educação. } \\
\text { - Rationales acadêmicas } \\
\text { e socioculturais para pro- } \\
\text { mover diálogos e superar } \\
\text { desigualdades entre os } \\
\text { povos. }\end{array}$ \\
\hline $\begin{array}{c}\text { Tipo de formação } \\
\text { almejada }\end{array}$ & $\begin{array}{l}\text { Formação do "cidadão } \\
\text { global". } \\
\text { - Educação profissional no } \\
\text { lugar da formação cidadã. } \\
\text { - Focada no desenvolvimento } \\
\text { individual, na competitivida- } \\
\text { de e na meritocracia; meio } \\
\text { para ascensão social. }\end{array}$ & $\begin{array}{l}\text { Formação do cidadão } \\
\text { reflexivo: político e ético. } \\
\text { - Educação não limitada } \\
\text { à técnica e à profissão, } \\
\text { mas focada no seu poten- } \\
\text { cial emancipatório. } \\
\text { - União de interesses indi- } \\
\text { viduais e coletivos. }\end{array}$ \\
\hline
\end{tabular}

Fonte: Adaptado a partir de Leal, Moraes e Oregioni (2018, p. 120 e 123). 
Apesar dessa construção dicotômica, trabalha-se "[...] com a ideia de hibridismos, de latências conflitivas, de coexistência de internacionalizações hegemônicas e contra-hegemônicas em um mesmo contexto" (LEAL; MORAES; OREGIONI, 2018, p. 124, grifo dos autores). Além disso, Leal, Moraes e Oregioni (2018, p. 124) salientam que a classificação de um projeto de internacionalização deve considerar questões empíricas e não "[...] apenas o discurso ou a intenção dos atores envolvidos".

A seguir, apresentamos o texto Chamada Pública que orienta o Programa de capacitação de professores de inglês, bem como tecemos algumas ponderações no tocante à sua perspectiva de internacionalização.

\section{O texto Chamada Pública como política de/para internacionalização da formação continuada de professores de inglês}

$\bigcirc$ ano de 2015 contou com resultados positivos no campo cultural e educacional entre Brasil e Estados Unidos. Foram assinados acordos bilaterais que contemplaram pautas de interesse dos dois países. Mais especificamente, o governo brasileiro, representado pela Secretaria de Educação Profissional e Tecnológica (SETEC), tornou público o Programa internacional de formação continuada de professores de inglês da RFEPCT, mediante ampla divulgação do texto Chamada Pública resultante do acordo SETEC-CAPES/NOVA.

Diante dessa perspectiva, adotamos a noção de sistemas de gênero como "[...] gêneros interrelacionados que interagem uns com os outros em ambientes específicos [...]" (BAZERMAN, 1994, p. 82) para afirmarmos que o texto Chamada Pública é um gênero precedido por outros gêneros que criaram condições institucionais adequadas para a sua materialização. Vejamos, a seguir, os arquitextos que compõem a rede discursiva do texto Chamada Pública: 


\section{Quadro 2 \\ Os arquitextos da Chamada Pública}

\begin{tabular}{|c|c|c|}
\hline AAl & $\begin{array}{c}\text { Decreto n } 7.692 \text { de } 2 \\
\text { de março de } 2012 .\end{array}$ & $\begin{array}{l}\text { Aprova o Estatuto e o Quadro Demonstrativo dos } \\
\text { Cargos em Comissão da CAPES e remaneja- } \\
\text { mento desses cargos. }\end{array}$ \\
\hline AA2 & $\begin{array}{c}\text { Decreto n } 7.690 \text { de } 2 \\
\text { de março de } 2012\end{array}$ & $\begin{array}{c}\text { Aprova o Estatuto e o Quadro Demonstrativo } \\
\text { dos Cargos em Comissão e das Funções } \\
\text { Gratificadas do Ministério da Educação. }\end{array}$ \\
\hline AA3 & $\begin{array}{l}\text { Lei } n^{\circ} 8.405 \text { de } 9 \text { de } \\
\quad \text { janeiro de } 1992 .\end{array}$ & $\begin{array}{l}\text { Autoriza o Poder Executivo a instituir a } \\
\text { Coordenação de Aperfeiçoamento de Pessoal } \\
\text { de Nível Superior (Capes), como fundação pú- } \\
\text { blica e outras providências. }\end{array}$ \\
\hline AA4 & $\begin{array}{l}\text { Decreto } n^{\circ} 7.176 \text { de } \\
12 \text { de maio de } 2010 \text {. }\end{array}$ & \begin{tabular}{|l} 
Dispóe sobre o acordo entre o Governo da \\
República Federativa do Brasil e o Governo dos \\
Estados Unidos da América para Programas \\
Educacionais e de Intercâmbio Cultural.
\end{tabular} \\
\hline AA5 & $\begin{array}{c}\text { Políticas linguísticas } \\
\text { Internacionais. }\end{array}$ & $\begin{array}{l}\text { Quadro Comum de Referência Europeu (QCRE, } \\
\text { 200 1) } \\
\text { Níveis do Marco Comum Europeu (NMCER) } \\
\text { Teste de Língua Inglesa como Língua Estrangeira } \\
\text { (TOEFL). }\end{array}$ \\
\hline
\end{tabular}

Fonte: Adaptado a partir de Cavalcante (2019, p. 339).

A Chamada Pública se tornou possível a partir dos documentos que regulamentam a CAPES. Desse modo, os arquitextos A1, A2 e A3 demonstram que essa agência é uma instituição pública que está legitimada para decidir sobre questões que interessam ao Estado brasileiro. Dentre essas questões, o arquitexto A3 aborda a política de formação docente, juntamente com a Lei $n^{\circ} 11.502$, de 11 de julho de 2007, que em seu parágrafo $2^{\circ}$ institui a CAPES como responsável por formular políticas de formação docente em diferentes níveis. Por fim, os arquitextos A4 e A5 evocam o edital da Chamada Pública, resultante do acordo de cooperação internacional entre Brasil e Estados Unidos (CAVALCANTE, 2019).

Segundo Cavalcante (2019), a rede discursiva que compõe o texto Chamada Pública se fundamenta em decretos e leis que incorporam políticas 
linguísticas estrangeiras às políticas educacionais brasileiras. Isso porque há uma escassez de políticas efetivas que tratem da implementação de políticas linguísticas e de idiomas e suas culturas nos cursos de formação de professores de línguas. Na prática, o governo brasileiro, em seus textos oficiais que regem o campo educacional, sofre grande influência de textos elaborados por organismos e instituições internacionais. Dessa forma, ocorre, unilateralmente, a reprodução de políticas educacionais estrangeiras na política educacional brasileira, resultante de tensões advindas de imperativos globais da internacionalização. A título de exemplificação, a aplicação do exame elaborado pelo Programa Internacional para Avaliação dos Estudantes (PISA), da OCDE, aos estudantes brasileiros permite observar que o País exige níveis satisfatórios de resultados dos estudantes sem ofertar condições educacionais para que isso aconteça.

Otexto Chamada Pública se instaura em uma ordem de discurso institucional cuja função é orientar os professores de inglês que pretenderam se inscrever na capacitação. Desse modo, a fim de discutirmos a perspectiva de internacionalização no referido texto, consideramos seus objetivos principais e específicos. Notadamente, nestes últimos, o termo " internacionalização" aparece não como objetivo materializado pelo verbo "internacionalizar", mas, sim, como ação secundária, de "pano de fundo", que ocorreria mediante a atuação dos participantes em seus respectivos campi, após o retorno da experiência nos Estados Unidos. Vejamos:

(1) Como contrapartida pela participação no Programa, os candidatos selecionados deverão atuar por meio de um plano de trabalho, por um período mínimo de um ano, nas ações do Programa ldiomas sem Fronteiras do Ministério da Educação, em sua instituição da Rede Federal ou em outras escolas das redes públicas no Brasil, de modo a aplicar os conhecimentos adquiridos e contribuir com ações e atividades de ensino, pesquisa, extensão, inovação e internacionalização, conforme detalhado a seguir (BRASIL, 2015, p. 1-2, grifo nosso).

Assim, percebemos na carga semântica dos verbos "atuar", "aplicar" e "contribuir" ações a serem desempenhadas pelos professores de inglês a fim de refletir na qualidade do ensino ofertado pela RFEPCT. Porém, a internacionalização, posicionada como um dos eixos a serem beneficiados pelo trabalho docente, não é evidenciada enquanto dimensão valorizada como tópico do 
Programa. Além disso, notamos que a internacionalização é projetada como um processo cuja responsabilidade é delegada unicamente ao docente, sem qualquer estratégia de sistematização e orientação por parte de uma equipe especializada, agência governamental ou em diálogo com o escritório de relações internacionais de cada instituição participante.

\section{Metodologia}

EEste trabalho orienta-se pela ADC (FAIRCLOUGH, 2003; 2016 RAMALHO; RESENDE, 2011 1), que considera que os textos suscitam discussões acerca das noções de discurso, poder e ideologia que envolvem os sistemas simbólicos de representação das práticas sociais.

A ADC constitui-se como teoria social do discurso que tem sido aplicada às pesquisas científicas sociais, sempre linguística e politicamente orientada para a mudança social, de modo que o discurso é analisado a partir do quadro tridimensional: texto, prática discursiva e prática social. Portanto, o discurso implica um modo de ação que os indivíduos aplicam para representar

12 o mundo e influenciar os outros. Há uma relação dialética de causa e efeito entre o discurso (prática social) e a estrutura social. Esta molda e restringe o discurso mediante as relações sociais, institucionais e as normas discursivas convencionadas. Todas as dimensões da estrutura social são direta ou indiretamente constituídas pelo discurso, de modo que este molda relações sociais, identidades e instituições (FAIRCLOUGH, 2016).

discurso é parte da prática social e expressa modos de ação, de representação e de ser. Dito de outra maneira, esses modos são construídos mediante "[...] a relação do texto com o evento, com o mundo social e físico mais amplo, e com as pessoas envolvidas no evento" (FAIRCLOUGH, 2003, p. 27). As representações discursivas sobre internacionalização dos professores participantes do Programa foram construídas dessa maneira.

A prática discursiva se constitui de modo convencional e criativo, o que "[...] contribui para reproduzir a sociedade (identidades sociais, relações sociais, sistemas de conhecimento e crença) como é, mas também contribui para transformá-la" (FAIRCLOUGH, 2016, p. 96). Apesar de alguns discursos se fixarem por estruturas sociais, há uma abertura a influências discursivas de outros sujeitos e espaços que podem provocar alterações em como os 
interagentes realizam uma prática. Isto posto, quando se analisa quaisquer textos, é essencial compreendê-los além do seu sentido amplo como linguagem falada ou escrita, pois os sentidos são construídos a partir de uma prática social que engloba aspectos políticos e ideológicos.

Os processos metodológicos de geração dos dados partiram da aplicação de um questionário estruturado, composto por 5 perguntas, por intermédio de uma plataforma digital e acompanhado por termo de consentimento livre e esclarecido de participação voluntária na pesquisa. $\bigcirc$ questionário está assim organizado: a primeira parte com questões de identificação dos participantes (gênero, idade, estado civil, filhos, tempo de docência na instituição e formação acadêmica); e uma segunda parte voltada para reflexões no tocante à internacionalização.

As perguntas do questionário são: 011 ○ que significa para você os processos de internacionalização da educação?; 02) Com base no texto da Chamada Pública do Programa SETEC-CAPES/NOVA, como você descreve a perspectiva de internacionalização da educação?; 03) Os processos de capacitação desenvolvidos pela CAPES em parceria com o Community College Consortium, representado pelo NOVA, contribuíram/contribuem para a sua prática docente no ensino da Língua Inglesa e em ações e atividades de internacionalização?; 4) Para uma sala de aula internacionalizada, quais estratégias são necessárias por parte do professor de inglês? e; 5) Tendo em vista os seus conhecimentos prévios a respeito da internacionalização da educação, sua atuação no curso de formação e sua prática como docente de Língua Inglesa, você considera que a Chamada Pública aborda, satisfatoriamente, a internacionalização da educação? Se sim, quais os pontos positivos? Se não, o que deveria abordar, mas que não desenvolveu? Neste artigo, consideramos os dados da primeira pergunta.

A Chamada Pública previa a seleção de até 152 (cento e cinquenta e dois) docentes, divididos em dois grupos de até 76 (setenta e seis) participantes cada que seriam selecionados em duas etapas. Os cursos se realizariam nos períodos de janeiro a março de 2016 (primeiro grupo) e de julho a agosto de 2016 (segundo grupo). Cada um desses grupos foi dividido em dois subgrupos, de modo a realizarem, respectivamente, a capacitação nas instituições San Francisco City College, na cidade de San Francisco (Califórnia - EUA), e Northern Virginia Community College, na cidade de Alexandria (Virgínia 
- EUA). Após o processo seletivo, 156 (cento e cinquenta e seis) docentes foram contemplados, 75 no primeiro grupo e 81 no segundo.

Embora o curso tenha sido realizado geograficamente em instituições distintas, a segunda instituição ficou responsável pelo desenho dos conteúdos, métodos e estratégias da capacitação. Observamos que o questionário de geração de dados para esta investigação foi aplicado apenas a 34 professores do primeiro grupo, que foram para a cidade de Alexandria, incluindo o primeiro autor deste artigo, que também respondeu ao questionário por ter feito parte do grupo. Já que esses professores interagem por um grupo no aplicativo WhatsApp, optamos por compartilhar o link de acesso ao questionário, juntamente com um termo de participação voluntária na pesquisa, para que fossem constituídos os materiais empíricos analíticos. Um e-mail com o questionário também foi enviado aos professores. Findo o prazo, recebemos 20 questionários respondidos.

Quanto à caracterização dos participantes, 55 \% são do sexo feminino e $45 \%$ do sexo masculino. Apresentam faixa etária entre 36 e 40 anos $(40 \%), 41$ e 50 anos (30\%), 25 e 35 anos (15\%) e acima de 50 anos (15\%). Acerca da formação acadêmica em nível de graduação, são licenciados com

14 habilitação em Letras Português/Inglês (60\%) e em Letras Inglês (35\%), ou possuem Bacharelado em Letras Português/Inglês (5\%). Na pós-graduação, os respondentes são mestres (60\%), doutores (35\%) e especialistas (5\%).

\section{As representações discursivas sobre internacionalização evidenciadas pelos professores de inglês}

Discutimos nesta seção as representações discursivas sobre internacionalização evidenciadas pelos professores de inglês a partir da compreensão de ideologia como concepção de mundo que se manifesta implicitamente na vida intelectual e coletiva (GRAMSCl, 2019), e de posse da máxima de que discursos são "[...] modos de representar os aspectos do mundo - os processos, as relações e as estruturas do mundo material, o 'mundo mental' dos pensamentos, dos sentimentos, das crenças e assim por diante, e o mundo social" (FAIRCLOUGH, 2003, p. 124).

A interdiscursividade se manifestou nos dados gerados e, por isso, foi eleita como categoria de análise. Ela se constitui pela presença de discursos 
diferentes, e até mesmo antagônicos, em um mesmo texto, o que ocorre pela escolha de palavras e de itens lexicais com a finalidade de estabelecer relações semânticas entre os elementos do texto, e também pela observação de outros aspectos como as pressuposições e as metáforas (FAIRCLOUGH, 2016). Nesse sentido, não se pode falar em discurso homogêneo, pois o locutor manipula os itens lexicais na luta por construir um discurso significativo com o intuito de evocar práticas que ordenem esse discurso e lhe possibilite agir em certo contexto (BATISTA JR.; SATO; MELO, 2018).

A interdiscursividade se relaciona aos significados representacionais. Por isso, fazemos as seguintes perguntas ao material empírico:

Quais discursos são articulados no texto e como são articulados? Há uma mistura significativa de discursos? Quais são os traços que caracterizam os discursos articulados (relações semânticas entre palavras, colocações, metáforas, presunções, traços gramaticais...)? (FAIRCLOUGH, 2003, p. 193, tradução nossa).

As respostas a essas perguntas indicam as possíveis representações de diferentes identidades discursivas. Para Ramalho e Resende (201 1, p. 170), "[...] a identificação de um discurso em um texto consiste na identificação de quais partes do mundo são representadas (os 'temas' centrais), e na identificação da perspectiva particular pela qual são representadas".

Observemos no quadro 3, as respostas à pergunta: "O que significa para você os processos de internacionalização da educação?". Devemos notar como as escolhas lexicais realizadas pelos participantes evidenciam a internacionalização a partir de dois eixos interdiscursivos. 


\section{Quadro 3 \\ Eixos interdiscursivos e itens lexicais}

\begin{tabular}{|l|}
\hline Internacionalização hegemônica \\
\hline (2) Dinamizar o processo de \\
ensino-aprendizagem utilizando \\
ferramentas de internacionalização \\
para tanto.
\end{tabular}

(4) Oportunidade de enriquecimento cultural e linguístico para alunos e professores.
Internacionalização contra-hegemônica

(3) Integração das ações da instituição com outras instituições no exterior, de forma a contribuir com o ensino, a pesquisa, a extensão e a qualificação dos professores.

(5) Possibilidade de crescimento pessoal e profissional, além da criação de um networking único [...] influencia diretamente na qualidade do meu trabalho entregue à comunidade.
(6) Consequência da globalização, uma vez que as mudanças em diversas áreas criaram a necessidade de se lidar com as novas condições impostas pela sociedade globalizada.

(8) Enviar e trazer professores e alunos para/de países diferentes.

(10) Fornece uma visão geral das principais tendências e estratégias educacionais globais.

(7) Troca de experiências que agreguem desenvolvimento à instituição e potencializem as oportunidades de formação acadêmica, profissional e humana aos sujeitos envolvidos.

(9) Compartilhar, colaborar e promover o desenvolvimento educacional de [...] instituições. Com isso, se permite também a aceitação da diversidade cultural que conforma o mundo.

(1 1) Vai além da mobilidade acadêmica e perpassa um novo olhar para o currículo, de modo que este tenha, como um de seus objetivos, o desenvolvimento de cidadãos globais com um nível [...] alto de competência intercultural.

(12) Políticas que tem como intuito permitir a mobilidade acadêmica de estudantes e preparação para inserção no mercado de trabal ho global.
(13) Significa mais políticas públicas e mais oportunidades de expansão do conhecimento. 


\section{Quadro 3}

Eixos interdiscursivos e itens lexicais (continuação)

\begin{tabular}{|c|c|}
\hline Internacionalização hegemônica & Internacionalização contra-hegemônica \\
\hline $\begin{array}{l}\text { (14) Oportunidade de expandir o } \\
\text { conhecimento, não apenas na teo- } \\
\text { ria, mas na prática. }\end{array}$ & $\begin{array}{l}\text { (15) Ampliação das possibilidades de } \\
\text { acesso a conhecimentos, de desenvolvi- } \\
\text { mento de consciência mais intercultural e } \\
\text { oportunidades de vivências plurais. }\end{array}$ \\
\hline $\begin{array}{l}\text { (16) Formas de garantir oportunida- } \\
\text { des de aprimoramento nos estudos e } \\
\text { na carreira [...]. Importante não só } \\
\text { para ampliar e melhorar os conhe- } \\
\text { cimentos técnicos, mas também os } \\
\text { contatos culturais entre diferentes lín- } \\
\text { guas e povos. }\end{array}$ & $\begin{array}{l}\text { (17) Trocas significativas entre instituições, } \\
\text { pessoas, estudantes, professores e acadê- } \\
\text { micos [...] de países diferentes [...], trocas } \\
\text { de experiências, de aprendizados [...], } \\
\text { aprimoramento [...] de saberes que, ao } \\
\text { serem compartilhados e globalizados, se } \\
\text { tornam muito mais humanizados também. }\end{array}$ \\
\hline $\begin{array}{l}\text { (18) Amplia o nosso olhar sobre o } \\
\text { trabalho docente, especialmente } \\
\text { quando abordamos questões cul- } \\
\text { turais e sócio-políticas [...], visa a } \\
\text { melhoria da qualidade no processo } \\
\text { de ensino e aprendizagem. }\end{array}$ & $\begin{array}{l}\text { (19) Cooperação internacional entre insti- } \\
\text { tuições [...] e com instituições estrangeiras } \\
{[\ldots] \text {, processos de ensino/aprendizagem, }} \\
\text { realização de pesquisas colaborativas que } \\
\text { permitem o desenvolvimento pessoal e pro- } \\
\text { fissional dos envolvidos. }\end{array}$ \\
\hline $\begin{array}{l}\text { (20) Oportunidade ímpar de imer- } \\
\text { são linguística e cultural essencial à } \\
\text { formação docente porque possibilita } \\
\text { interações reais na cultura da lín- } \\
\text { gua estrangeira, contribuindo para } \\
\text { a (des)construção de percepções } \\
\text { dessa cultura, lançando, assim, mais } \\
\text { luz sobre a nossa própria cultura } \\
\text { e aprofundando [...] nosso senso } \\
\text { crítico-reflexivo. }\end{array}$ & $\begin{array}{l}\text { (21) Infundir uma perspectiva internacional } \\
{[\ldots] \text { em uma instituição de ensino }[. . .] \text { a fim }} \\
\text { de contribuir com o desenvolvimento da } \\
\text { sociedade. }\end{array}$ \\
\hline
\end{tabular}

Fonte: Dados da pesquisa (2020).

Pode-se notar nos excertos selecionados que os participantes se valeram de diferentes entidades para nominalizar a sua compreensão a respeito do processo de internacionalização, tendo em vista suas perspectivas de mundo, suas identidades pessoais e sociais e suas relações com outras pessoas 
Representações discursivas sobre internacionalização por professores de inglês em formação continuada

(FAIRCLOUGH, 2003), incluindo as relações que estabelecem a partir do discurso institucional que compartilham por serem professores da RFEPCT. Assim, embora todas as conceituações apresentadas pelos professores de inglês participantes possam facilmente serem classificadas como positivas, há representações discursivas hegemônicas e contra-hegemônicas que as permeiam, ainda que indiretamente.

$\bigcirc$ uso de entidades nominais para designar processos é explicado por Fairclough (2003), no sentido de que os processos são "nominalizados" e podem ser classificados como "nominalizações" ou "substantivos de processo", ou seja, substantivos com a qualidade de verbos. Entretanto, conforme se percebe nos excertos (2), (8), (9), (10), (1 1), (18) e (21), os respondentes aplicam entidades verbais para designarem o processo de internacionalização, o que pode estar relacionado à questão de que verbos possuem força ilocucionária de ação mais significativa.

Desenvolvemos um pouco mais a análise considerando que, para os procedimentos de análise da ADC, "[...] é mais produtivo focar em como diferentes discursos estruturam o mundo, e, portanto, em relações semânticas entre as palavras" (FAIRCLOUGH, 2003, p. 129), a saber: sinonímia, hiponímia 18 e antonímia. Além disso, a discussão teórica da IC estimula enfrentamentos diante das imposições e naturalizações advindos da ordem de discurso neoliberal colonialista e mercantilista de sociedade.

Segundo Souza (2018), o processo de globalização vigente no mundo capitalista estimula uma internacionalização pautada por princípios naturalizados de hegemonia e homogeneidade cultural, contra os quais parece impossível resistir devido à ausência de alternativas. Dessa forma, a globalização passa a orientar a internacionalização, ora pelo imperativo econômico, ora pelo social, o que significa que a diferença está no alinhamento que países e instituições promovem com um discurso neoliberal que visa o lucro, ou com um discurso de coesão social. Este pode ser reconstruído de uma ótica econômica como "[...] qualidade humana e habilidade de se trabalhar em equipe e como fonte de eficiência e adaptabilidade" (FAIRCLOUGH, 2003, p. 128). Ademais, de acordo com Fairclough (2003, p. 128), "[os] diferentes discursos implicam prioridades políticas diferentes - políticas para aprimorar a competitividade por um lado, e a coesão social por outro". 
No que concerne ao eixo discursivo da "internacionalização hegemônica", encontramos frases e enunciados nominais como: "oportunidade de enriquecimento cultural" (4), "consequência da globalização" (6), "políticas que tem como intuito a mobilidade de estudantes" e "preparação para inserção no mercado de trabalho global" (12), "oportunidade de expandir o conhecimento" (14), "formas de garantir oportunidades de aprimoramento nos estudos e na carreira" (16), "melhoria da qualidade no processo de ensino e aprendizagem" (18) e "oportunidade ímpar de imersão linguística e cultural essencial à formação docente" (20). Essas escolhas lexicais evocam uma abordagem instrumentalista de internacionalização com atividades, objetivos e arranjos que se configuram dentro de uma orientação político-econômica que estimula a competitividade entre os estudantes, assegurando a manutenção desse modelo de economia global (VAVRUS; PEKOL, 2015).

Assim, é necessário refletir sobre o fato de que os discursos hegemônicos de poder estão infundidos no "coração" da internacionalização, pois até mesmo os professores participantes desta pesquisa, que já passaram por uma formação continuada internacionalizada e em sua maioria possuem sólida formação acadêmica, reproduzem representações discursivas eurocêntricas e coloniais em suas falas. As escolhas lexicais hegemônicas dos participantes informam uma internacionalização que se relaciona com o que Stein (2019) classifica como neutra, inevitável e responsiva a padrões contemporâneos de globalização.

No eixo da "internacionalização contra-hegemônica", os professores também fizeram uso de algumas construções nominais como: "integração das ações da instituição com outras instituições no exterior" (3), "possibilidade de crescimento pessoal e profissional" e "qualidade do meu trabalho entregue à comunidade" (5), "troca de experiências que agreguem desenvolvimento à instituição" e "oportunidades de formação acadêmica, profissional e humana aos sujeitos" (7), "desenvolvimento educacional" e "aceitação da diversidade cultural que conforma o mundo" (9), "vai além da mobilidade acadêmica" e "desenvolvimento de cidadãos globais com um nível alto de competência intercultural" (1 1), "políticas públicas" e "oportunidades de expansão do conhecimento" (13), "ampliação das possibilidades de acesso a conhecimentos", "desenvolvimento de consciência mais intercultural" e "oportunidades de vivências plurais" (15), "trocas significativas entre instituições, pessoas, estudantes, professores e acadêmicos [...] de países diferentes", "troca de experiências" e 
Representações discursivas sobre internacionalização por professores de inglês em formação continuada

"construção de saberes que, ao serem compartilhados e globalizados, se tornam humanizados" (17), "cooperação internacional entre instituições [...] com instituições estrangeiras", "processos de ensino/aprendizagem", "realização de pesquisas colaborativas" e "desenvolvimento pessoal e profissional" (19), e "desenvolvimento da sociedade" (21). As escolhas lexicais posicionadas no eixo contra-hegemônico indicam sentidos de uma internacionalização que visa a minimizar as diferenças de privilégios entre os grupos e estimular atividades colaborativas (VAVRUS; PEKOL, 2015), bem como se pauta por valores como parceria, troca e benefício mútuo (STEIN, 2019).

A análise aponta duas perspectivas distintas que orientam as representações discursivas dos participantes no tocante às compreensões que têm acerca da internacionalização, partindo de suas experiências no âmbito do Programa internacional de formação continuada de professores de inglês da RFEPCT. Por um lado, tem-se um discurso naturalizado, impositivo e inevitável de internacionalização, legitimado pela concepção de globalização como fenômeno que estimula o progresso econômico do estado-nação por intermédio da pauta educacional. Essa internacionalização, descrita como "hegemônica", se materializa por intermédio de práticas instrumentalistas e funcionalistas. Por

20 outro lado, os dados analisados evidenciaram representações discursivas que também informam uma internacionalização "contra-hegemônica", motivada por movimentos de troca, de colaboração e de justiça social. Nessa perspectiva, o desenvolvimento humano e social é reconhecido como dimensão que pode ser estimulada pela internacionalização.

Ressaltamos que a dicotomia "[...] internacionalização hegemônica" versus "internacionalização contra-hegemônica [...]" não é bem definida, podendo seus descritores coexistirem de maneira híbrida e conflitiva (LEAL; MORAES; OREGIONI, 20 18). Constata-se isso nos excertos: (4), (16), (18) e (20), os quais apresentam elementos frasais relacionados ora às concepções de enriquecimento, capacitação, melhoria de qualidade, ora às de troca linguística e cultural, abordagem cultural e sociopolítica e oportunidade de reflexão crítica. Desse modo, considera-se tarefa complexa delimitar os sentidos presentes nas representações discursivas construídas pelos professores participantes da pesquisa acerca da internacionalização. 


\section{Considerações finais}

Neste artigo, analisamos as representações discursivas de internacionalização reverberadas por um grupo de professores de inglês da Rede Federal de Educação Profissional Científica e Tecnológica (RFEPCT) participante do Programa SETEC-CAPES/NOVA de formação continuada.

Seguindo as orientações teórico-metodológicas da Análise de Discurso Crítica e dos estudos de Internacionalização Crítica, percebemos, pela análise dos dados, que os professores em questão construíram interdiscursos da internacionalização pautados pela concepção de globalização como fenômeno inevitável que estabelece os modos de operação de uma economia altamente baseada na lógica de mercado.

Entretanto, as ideologias de poder sinalizadas pelas escolhas lexicais dos participantes evidenciaram dois eixos de representação discursiva, o da internacionalização hegemônica que valoriza os resultados e principalmente estimula atividades de mobilidade acadêmica internacional, e o eixo da internacionalização contra-hegemônica, que valoriza estratégias colaborativas e práticas que impactam o desenvolvimento da sociedade.

A partir dos dados, consideramos tarefa complexa delimitar hegemonias e contra-hegemonias nas representações discursivas reverberadas pelos professores participantes acerca da internacionalização, pois sentidos híbridos e conflitivos coexistem nessas representações.

\section{Referências}

BATISTA JR., José Ribamar Lopes; SATO, Denise Tamaê Borges; MELO, Iran Ferreira. (org.). Análise de discurso crítica para linguistas e não linguistas. São Paulo: Parábola, 2018.

BAZERMAN, Charles. Systems of Genres and the Enactment of Social Intentions. In: FREEDMAN, Aviva; MEDWAY, Peter. Genre and the new rhetoric. London: Taylor \& Francis, 1994.

BRANDENBURG, Uwe.; DE WIT, Hans. The End of Internationalization. International Higher Education. Chestnut Hill, v. 1, n. 62, p. 15-16, dec./feb. 2011 . Disponível em: https:// ejournals.bc.edu/index.php/ihe/article/view/8533. Acesso em: 20 jul. 2020.

BRASIL. Lei $\mathbf{n}^{\circ} \mathbf{1 1 . 5 0 2}$, de 11 de julho de 2007. Disponível em: http://www. planalto.gov. br/ccivil_03/_ato2007-2010/2007/lei/l1 1502.htm. Acesso em: 06 jul. 2021. 
BRASIL, Decreto $\mathbf{n}^{\circ} \mathbf{7 . 1 7 6}$, de 12 de maio de 2010. Disponível em: https://www. planalto. gov.br/ccivil_03/_ato2007-2010/2010/decreto/d7176.htm. Acesso em: 06 jul. 2021 BRASIL. Chamada Publica SETEC/MEC no 01/2015, de 22 de setembro de 2015. Retificação de 01 de junho de 2016. Disponível em: http://portal.mec.gov. br/escola-de-gestores-da-educacao-basica/ 190 -secretarias- 112877938 / setec-1749372213/46021-editais-setec-2015. Acesso em: 10 abr. 2021.

CAVALCANTE, Rivadavia Porto. Política linguística e formação de professores de inglês no contexto da cooperação Brasil-Estados Unidos. In: SOUSA, Socorro Cláudia Tavares de; PONTE, Andrea Silva; SOUSA-BERNINI, Emny Nicole B. de. (org.). Fotografias da política linguística na pós-graduação no Brasil. João Pessoa: Editora UFPB, 2019.

DINIZ-PEREIRA, Júlio Emílio; ZEICHNER, Kenneth M. Justiça social: desafio para a formação de professores. Belo Horizonte: Autêntica, 2008.

DUTRA, Deise Prina. Os passos da pesquisa em formação de professores de línguas no Brasil. In: SILVA, Kléber Aparecido; MASTRELLA-DE-ANDRADE, Mariana; PEREIRA FILHO, Cesário Alvim (org.). A formação de professores de línguas: políticas, projetos e parcerias. Campinas: Pontes, 2015.

FAIRCLOUGH, Norman. Analysing discourse. Textual analysis for social research. LondresNova York: Routledge, 2003.

22 FAIRCLOUGH, Norman. Discurso e mudança social. Brasília: Editora Universidade de Brasília, 2016.

GRAMSCl, Antonio. Cadernos do cárcere. Rio de Janeiro: Civilização Brasileira, 2019. (V. 1).

LEAL, Fernanda Geremias; MORAES, Mário César Barreto; OREGIONI, Soledad. Hegemonia contra hemonia no contexto da educação superior: Critérios para uma análise crítica e reflexiva do campo.Integración y Conocimiento, Córdoba, v. 7, n. 2, p. 150-166, jun./dez. 2018. Disponível em: https://revistas.unc.edu.ar/index.php/integracionyconocimiento/ article/view/21929. Acesso em: 21 abr. 2021.

LIMA, Manolita Correia; CONTEL, Fabio Betioli. Internacionalização da educação superior: nações ativas, nações passivas e a geopolítica do conhecimento. São Paulo: Alameda, 2011.

LIMA, Manolita; MARANHÃO, Carolina. $\bigcirc$ sistema de educação superior mundial: entre a internacionalização ativa e passiva. Avaliação, Campinas/Sorocaba, v. 14, n. 3, p. 583-610, nov. 2009. Disponível em: https://www.scielo.br/scielo.php?.pid=S1414$-40772009000300004 \&$ script=sci_abstract\&tlng=pt. Acesso em: $1^{\circ}$ dez. 2020. 
MAGALHÃES, Izabel. Introdução: a análise de discurso crítica. DELTA, São Paulo, v. 21, n. especial, p. 1-9, 2005. Disponível em: https://doi.org/10.1590/S010244502005000300002. Acesso em: 12 dez. 2020.

MOROSINI, Marilia. Guia para a Internacionalização Universitária. Porto Alegre: EDIPUCRS, 2019.

NEZ, Egeslaine de; FRANCO, Maria Estela Dal Pai. Geopolítica do conhecimento na pós-graduação brasileira. In: GIANEZINI, Kelly; LAUXEN, Sirlei de Lourdes; VOLPATO, Gildo; FRANCO, Maria Estela Dal Pai (org.). Educação superior: políticas públicas e institucionais em perspectiva. Florianópolis: Dois Por Quatro; Criciúma: UNESC, 2018.

PERROTTA, Daniela. La internacionalización de la universidad: debates globales, acciones regionales. Los Polvorines: Universidad Nacional de General Sarmiento; Ciudad Autónoma de Buenos Aires: Instituto de Estudios y Capacitación-IEC-CONADU, 2016.

RAMALHO, Viviane; RESENDE, Viviane Melo. Análise de discurso (para a) crítica: o texto como material de pesquisa. Campinas: Pontes Editores, 2011.

SOUZA, Cláudia Schiedeck Soares. Os institutos federais e a internacionalização: concepções, reflexões e desafios. In: SOUZA, Carlos Fabiano; MANHÃES, Elane Kreile (org.).

Olhares em rede: diálogos oportunos no âmbito do ensino e da aprendizagem de inglês na rede federal tecnológica. Curitiba: Appris, 2018.

STEIN, Sharon. Critical internationalization studies at an impasse: making space for complexity, uncertainty, and complicity in a time of global challenges. Studies in Higher Education, London, v. 44, n. 1, dec. 2019. Disponível em: http://doi.org/10.1080/03075079.20 19.1704722. Acesso em: 16 jul. 2020.

VAVRUS, Frances; PEKOL, Amy. Critical internationalization: moving from theory to practice.

FIRE - Forum for International Research in Education, Bethlehem, v. 2, n. 2, jan. 2015. Disponivel em: https://doi.org/10.18275/fire201502021036. Acesso em: 16 jul. 2020.

Prof. Ms. Lauro Sérgio Machado Pereira Instituto Federal do Norte de Minas Gerais (Brasil) Doutorando pelo Programa de Pós-Graduação em Linguística (PPGL/UnB) Grupo de Estudos Críticos e Avançados em Linguagem (GECAL/UnB) Orcid id: https:/ / orcid.org/0000-0002-7144-2733 E-mail: lauro.pereira@ifnmg.edu.br 
Artigo

Representações discursivas sobre internacionalização por professores de inglês em formação continuada

Prof. Dr. Kléber Aparecido da Silva

Universidade de Brasília (Brasil)

Programa de Pós-Graduação em Linguística (PPGL/UnB)

Grupo de Estudos Críticos e Avançados em Linguagem (GECAL/UnB)

Orcid id: https: / / orcid.org/0000-0002-78 1 5-7767

E-mail: kleberunicamp@yahoo.com.br

Recebido 20 maio 2021

Aceito 6 jul. 2021 